\title{
Assessment of dye distribution in sensitized solar cells by microprobe techniques
}

\author{
M.A. Barreiros ${ }^{a}, *$, V. Corregidor ${ }^{b}$, L.C. Alves ${ }^{c}$, F. Guimarães ${ }^{d}$, J. Mascarenhas ${ }^{\text {a }}$, E. Torres ${ }^{\text {a }}$, M.J. Brites ${ }^{\text {a }}$ \\ a Laboratório Nacional de Energia e Geologia, LEN/UES, Estrada do Paço do Lumiar, 22, 1649-038 Lisboa, Portugal \\ b IPFN, Instituto Superior Técnico, Universidade de Lisboa, E.N. 10, 2686-953 Sacavém, Portugal \\ ${ }^{\mathrm{C}}$ C2TN, Campus Tecnológico e Nuclear, Instituto Superior Técnico, Universidade de Lisboa, E.N. 10, 2686-953 Sacavém, Portugal \\ ${ }^{\mathrm{d}}$ Laboratório Nacional de Energia e Geologia, LGM/UCTM, Rua da Amieira, Apartado 1089, 4466-901 S. Mamede de Infesta, Portugal
}

\section{A R T I C L E I N F O}

\section{Article history:}

Received 4 July 2014

Received in revised form 24 September 2014

Accepted 12 November 2014

Available online $\mathrm{xxxx}$

\section{Keywords:}

Dye sensitized solar cells

Dye load

Dye distribution

Microprobe techniques

\begin{abstract}
A B S T R A C T
Dye sensitized solar cells (DSCs) have received considerable attention once this technology offers economic and environmental advantages over conventional photovoltaic (PV) devices. The PV performance of a DSC relies on the characteristics of its photoanode, which typically consists of a nanocrystalline porous $\mathrm{TiO}_{2}$ film, enabled with a large adsorptive surface area. Dye molecules that capture photons from light during device operation are attached to the film nanoparticles. The effective loading of the dye in the $\mathrm{TiO}_{2}$ electrode is of paramount relevance for controlling and optimizing solar cell parameters. Relatively few methods are known today for quantitative evaluation of the total dye adsorbed on the film. In this context, microprobe techniques come out as suitable tools to evaluate the dye surface distribution and depth profile in sensitized films. Electron Probe Microanalysis (EPMA) and Ion Beam Analytical (IBA) techniques using a micro-ion beam were used to quantify and to study the distribution of the Ru organometallic dye in $\mathrm{TiO}_{2}$ films, making use of the different penetration depth and beam sizes of each technique. Different 1D nanostructured $\mathrm{TiO}_{2}$ films were prepared, morphologically characterized by SEM, sensitized and analyzed by the referred techniques. Dye load evaluation in different $\mathrm{TiO}_{2}$ films by three different techniques (PIXE, RBS and EPMA/WDS) provided similar results of Ru/Ti mass fraction ratio. Moreover, it was possible to assess dye surface distribution and its depth profile, by means of Ru signal, and to visualize the dye distribution in sample cross-section through X-ray mapping by EPMA/EDS. PIXE maps of Ru and Ti indicated an homogeneous surface distribution. The assessment of Ru depth profile by RBS showed that some films have homogeneous Ru depth distribution while others present different Ru concentration in the top layer $(2 \mu \mathrm{m}$ thickness). These results are consistent with the EPMA/EDS maps obtained.
\end{abstract}

(c) 2014 Elsevier B.V. All rights reserved.

\section{Introduction}

The world is in great need of technologies providing renewable energy. Solar energy which is abundant and clean is of great interest among the choices of sustainable and renewable energy. Dye sensitized solar cells (DSCs) based on polypiridyl ruthenium(II) complex dyes adsorbed on $\mathrm{TiO}_{2}$ electrode have received considerable attention since the pioneering work of Gratzel and O'Regan [1]. This technology offers economic and environmental advantages over conventional photovoltaic (PV) devices because they can be manufactured with low-cost technologies and in an energyefficient and eco-friendly manner.

\footnotetext{
* Corresponding author. Tel.: +351210924781.

E-mail address: alexandra.barreiros@lneg.pt (M.A. Barreiros).
}

Along the last two decades, significant progress has been made and best power conversion efficiency of the DSCs at the laboratory scale has surpassed $12 \%$ [2].

A typical DSC is constructed with a dye-sensitized mesoporous wide band gap semiconductor electrode, such as $\mathrm{TiO}_{2}$ or $\mathrm{ZnO}$, a liquid electrolyte containing $\mathrm{I}^{-} / \mathrm{I}^{3-}$ redox couple and platinum coated fluorine doped tin oxide (FTO) counter electrode.

The PV performance of a DSC relies on the characteristics of its photoanode, which plays a central role in converting light into electrical energy. A DSC photoanode usually consists of a nanocrystalline porous $\mathrm{TiO}_{2}$ film, enabled with a large adsorptive surface area. Dye molecules that capture photons from light during device operation are attached to the film nanoparticles. Thus, an oxide film with a large interfacial surface area and superior electron transport properties is vital for strong light harvesting and efficient device 